\title{
GADGET ADDICTION AND THE EFFECT OF SLEEP HABIT, STRESS, PHYSICAL ACTIVITY TO OBESITY
}

\author{
Oktia Woro Kasmini Handayani ${ }^{1}$, Ari Yuniastuti ${ }^{2}$, Komaria Ode Abudu ${ }^{3}$ and Efa Nugroho ${ }^{1}$ \\ ${ }^{1}$ Department of Public Health Science, Universitas Negeri Semarang, Indonesia, 50229 \\ ${ }^{2}$ Department of Biology, Universitas Negeri Semarang, Indonesia, 50229 \\ ${ }^{3}$ Post Graduate Program, Universitas Negeri Semarang, 50229
}

Corresponding author: Oktia Woro Kasmini Handayani

Email: oktia_woro@yahoo.com

\begin{abstract}
Obesity become worrying problem among adolescents, they who are obesed are $80 \%$ have the opportunity to experience obesity as adults and have higher risk of serious diseases such as cardiovascular disease, stroke, diabetes, asthma, and some types of cancer. According to the health profile of Yogyakarta Special Province in 2017 the prevalence of obesity was $19.1 \%$ occurs in adolescents. The main purpose of the research is to analyze the direct and indirect effects of gadget usage, sleep habit, stress, and physical activity on obesity. The population in this research was obese junior and senior high school adolescents, totaling 150 persons. Determination of samples is taken by simple random sampling. Independent variables consist of gadget usage, stress level, sleep habit, and physical activity. While the dependent variable is obesity. Bivariate analysis with chi-square test is applied for cathegorical data and independent $T$-test for numerical data. Multivariate analysis is carried out with path analysis, using the Amos version 22.0 software program. The results of this research found that the conclusions of the path diagram generated are as follow: 1) Gadget usage variable path coefficient value has a positive effect on physical activity. 2) Physical activity variable path coefficient value has a positive in effect on obesity. 3) Sleep habit and stress variable path coefficient value has a positive effect on gadget usage. It can be concluded that gadget addiction is directly related to sleep habits, stress, physical activity, and indirectly with obesity.
\end{abstract}

Keywords: Gadget, Stress, Physical activity, Obesity, Adolescents

\section{INTRODUCTION}

Nowadays, over nutrition status (obesity) become a serious problem. The secular trend of obesity can be said to occur throughout the world. Within 25 years, between 1976 and 1999, there was a doubling of obesity rates in children aged 6 to 11 years, and as many as three times in adolescents and this is a global problem ${ }^{1}$. Obesity that occurs is related to the mortality and the risk of metabolic and cardiovascular diseases and causes a loss of financing for high lifetime treatment. Obesity in adolescents is important to note because adolescents who are obese, $80 \%$ have the opportunity to experience obesity as adults.

WHO data shows that obesity is estimated to cause 2.8 million deaths or $5.2 \%$ of the total annual mortality in the world ${ }^{2}$. Obesity, measured through a body mass index (BMI), can cause metabolic disorders in blood pressure, cholesterol, triglycerides, and insulin resistance. The risk of coronary heart disease, ischemic stroke, and type 2 diabetes mellitus are increased along with increasing body mass index (BMI).

Obesity in adolescents is important to note because adolescents who are obese $80 \%$ have the opportunity to experience obesity as adults. Adolescents who are obese throughout their lives will be at higher risk of experiencing several serious diseases such as cardiovascular disease, stroke, diabetes, asthma, and some types of cancer $^{3}$. Obesity prevalence in adolescents aged 16-18 years in Indonesia from 2009 to 2013 has increased, from $2.8 \%$ to $7.3 \%{ }^{4,5}$.

The results showed that the factors that influence the incidence of obesity, namely playing gadgets for 1-3 hours a day tend to increase the risk of obesity by $30 \%$. Too often interacting with electronic devices, causing someone to be passive, not much movement and could be a factor in the emergence of obesity 6,7 . Teenagers who still carry gadgets until their beds will have less sleep time. In the age range of $18-65$ years with less than 7 hours of sleep per day showing a higher body mass index (BMI), on one side a longer sleep time that is not accompanied by physical activity and reduced energy intake could also increase $\mathrm{BMI}^{8-10}$. Another factor that affects obesity is stress, the results of a study found $37 \%$ of adolescents overeating during stress due to habits and 33\% because it helps divert their attention from the causes of stress.

Increasingly advanced technology causes lifestyle changes that cannot be avoided, particularly in adolescents, including the habit of playing gadgets, eating habbit, physical activity, and their effects. The purpose of this research was to analyze the direct and indirect effects of the use 
of gadgets, sleep habit, diet, stress and physical activity on obesity.

\section{METHODS}

The research was conducted in Yogyakarta Special Region which is one of fifteen provinces in Indonesia with obesity prevalence above national prevalence, and Yogyakarta City is an area that has many obese patients compared to other districts with a prevalence of $4.81 \%$. The research used a quantitative approach with cross sectional design. Independent variables consist of gadgets usage, stress levels, sleep habit, and physical activity, while the dependent variable is Obesity.

\section{Participants}

The population in this study was adolescents of junior and senior high school who were obese with an age range between $12-18$ years, totaling 150 people and were in the city of Yogyakarta. The sample was determined by simple random sampling, while the sample size was determined by the Yamane/Slovin formula ${ }^{11}$.

\section{Instruments}

The instruments in this study consisted of self structured questionnaires, physical activity recall forms, food recall forms, and weight scales. The instrument has been tested for validity and reliability.

\section{Procedures}

Instrument in the form of a questionnaire was measured by validity test using the Product Moment correlation formula and reliability with the Cronbach Alpha statistical test ${ }^{12,13}$. The bivariate analysis with chi-square test was applied for categorical data and independent T-test was applied for numerical data. Multivariate analysis was performed with path analysis to determine the direct and indirect effects of a set of exogenous variables on endogenous variables, using the Amos version 22.0 software program.

\section{RESULTS}

Based on research result, $63.3 \%$ of respondents were male, with the most at the age of 16 and 17 years, which were $18.3 \%$ each. The most of gadget usage is at the moderate level $(70.5 \%)$, with the most stress at the low level $(93.6 \%)$, the most sleep habit at the low level $(83.5 \%)$, as the most physical activity at the moderate level (46.8\%). The complete data is presented in the table 1.

Table 1: Socio-demographic characteristics of the respondents

\begin{tabular}{lcc}
\hline Characteristics & Respondents & Percentage \\
\hline Sex & \multicolumn{1}{c}{} \\
Male & 69 & $63.3 \%$ \\
Female & 40 & $36.7 \%$ \\
\hline Age & 11 & $10.1 \%$ \\
12 years & 18 & $16.5 \%$ \\
13 years & 19 & $17.4 \%$ \\
14 years & 16 & $14.7 \%$ \\
15 years & 20 & $18.3 \%$ \\
16 years & 20 & $18.3 \%$ \\
17 years & 5 & $4.6 \%$ \\
18 years & & \\
\hline Gadget usage & 2 & $1.8 \%$ \\
Low & 79 & $72.5 \%$ \\
Medium & 28 & $4.6 \%$ \\
High & & \\
\hline Stress & 102 & $93.6 \%$ \\
Low & 7 & $6.4 \%$ \\
Medium & 0 & $4.6 \%$ \\
High & & \\
Sleep habit & 15 & $13.8 \%$ \\
Poor & 91 & $83.5 \%$ \\
Lack & 3 & $2.8 \%$ \\
Good & & \\
\hline Physics Activity & 14 & $12.8 \%$ \\
Light & 51 & $46.8 \%$ \\
Medium & 44 & $40.4 \%$ \\
Heavy & & \\
\hline
\end{tabular}


After testing the normality of the data and statistical tests obtained path diagrams and estimated effects between variables, with the results of 6 of 7 testing the influence between exogenous and endogenous variables is not significant, so it is necessary to analyze the trimming model, so that the path model becomes appropriate and accurate. So that the path diagram generated is according to Figure. 1.

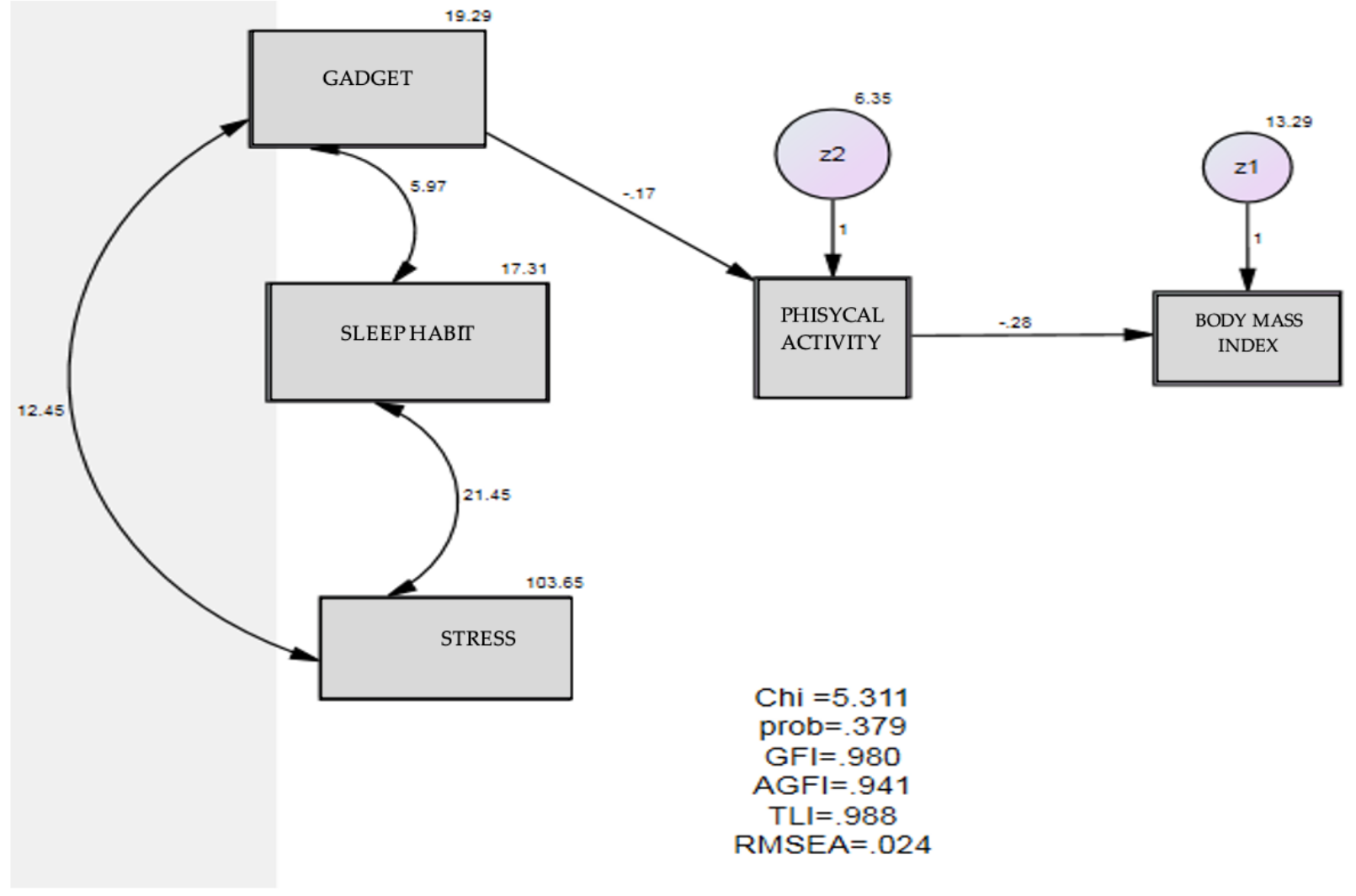

Figure 1. Path Diagram

In statistics, path analysis is used to describe the directed dependencies among a set of variables. This includes models equivalent to any form of multiple regression analysis, factor analysis, canonical correlation analysis, discriminant analysis, as well as more general families of models in the multivariate analysis of variance and covariance analyses.

The purpose of using path analysis is to see the relationship between variables based on a priori model. Explain why the variables are correlated using a temporal sequential model. Draw and test a mathematical model using the underlying equations. Identify the pathway that causes a certain variable to influence other variables. Calculating the influence of one or more exogenous independent variables on the other endogenous dependent variables.

After the research variables were analyzed using path analysis and presented using a path diagram, then the data were summarized in table 2 . There was a correlation between use of Gadget with stress, use of gadget with sleep habit, and stress with sleep habit.

Table 2: Result of correlation between gadget usage, sleep habit and stress

\begin{tabular}{lcc}
\hline Inter Variables Correlation & Estimation & Probability \\
\hline Gadget $<-$ - > stres & 0.279 & 0.006 \\
Gadget $<-$-> sleep habit & 0.327 & 0.001 \\
Stress $<-$-> sleep habit & 0.506 & 0.000 \\
\hline
\end{tabular}


The correlation between gadget usage and stress is 0.279 , so the relation between gadget usage with stress is quite strong and in the same direction, if the gadget usage is high then the stress level is also high, and vice versa. The correlation of these two variables has a probability of $0.006<0.05$ or the correlation between the two variables has a significant effect.

The correlation between gadget usage and sleep habit is 0.327 , so the relation between gadget usage with sleep habit is quite strong and in the same direction, if the gadget usage is high then sleep habit will be bad, and vice versa. The correlation of these two variables has a probability of $0.001<0.05$ or the correlation between the two variables has a significant effect.

The correlation between stress level and sleep habit is 0.506 , so the relation between stress level with sleep habit is strong and unidirectional, if stress is high then sleep habit will be bad, and vice versa. The correlation of these two variables has a probability of 0.000 $<0.05$ or the correlation between the two variables has a significant effect.

Table 3. Result of correlation between gadget usage to physical activity (PI) and physical activity (PI) to Obesity

$\begin{array}{llll}\text { Intervariables Correlation } & \text { Estimation } & \text { Probability } & \text { R Square }\end{array}$

\begin{tabular}{llll}
\hline $\mathrm{PI}<---$ Gadget & -.170 & .002 & .081 \\
$\mathrm{BMI}<---\mathrm{PI}$ & -.284 & .035 & .040 \\
\hline
\end{tabular}

The effect of the gadget usage variable on physical activity is simultaneously $8.1 \%$, while the remaining $91.9 \%$ is influenced by other variables outside of this model. From the above can be seen that when the gadget usage increase then physical activity decreases, this is supported by the estimation value of $-17 \%$.

Statistical results show that the physical activity variable affect obesity $4.0 \%$ simultaneously, while the remaining $96.0 \%$ is influenced by other variables outside of this model. From the above can be seen that when physical activity is low then obesity will increase by $4.0 \%$, this is supported by the estimation value of $-28.4 \%$.

From the hypothesis test in this study was obtained: 1) the variable coefficient of gadget usage was -0.170 and the signification of the gadget usage variable was $0.002<0.05$, meaning that there is a significant effect of gadget usage variable on physical activity variable. 2) the variable coefficient of physical activity was -0.284 and the signification of the physical activity variable was $0.035<0.05$, meaning that there is a significant effect of the physical activity variable on the obesity variable.

The interpretation of the model or path analysis equation resulted is as below:

1) The direct effect of $X 1$ to $X 4$, the effect of gadget usage variable $(X 1)$ on physical activity $(X 4)$ is equal to $-0,170$

2) The direct effect of $X 4$ to $Y 1$, the effect of physical activity variable (X4) on obesity (Y1) is equal to -0.280
3) The indirect effect of gadget usage (X1),

sleep habit $(X 2)$, stress $(X 3)$ through physical activity (X4) on obesity (Y1) is $\mathrm{X} 1+\mathrm{X} 2+\mathrm{X} 3+\mathrm{X} 1 \mathrm{X} 4+\mathrm{X} 4+\mathrm{X} 4 \mathrm{Y} 1 \quad(5.97+21.45$ $+12,45+-0,170+6,35+-0,280)$

\section{DISCUSSION}

Effect of Gadget, Physical Activity and Obesity The gadget usage has a direct effect on physical activity which is $8.1 \%$, while the remaining $91.9 \%$ is affected by other factors such as age, environment, work, and health status. The result shows that most of the teenagers who were respondents $(63 \%)$ had more than one gadget used 3 hours / day and made the teenagers become lazy to do activities, this was because teenagers had many game content and communication programs through social media, making them addicted to operate the gadget. Though most respondents use gadget in the medium cathegory (72.5\%). Decreasing and low levels of physical activity are believed to be one of the things that cause obesity.

Current technological developments strongly support the development of gadgets becoming increasingly varied, increasingly attractive and tempting, and able to reach all walks of life, including adolescents. Playing gadget can make a person sit quietly for hours, thus reducing physical activity. Most children and adolescents have access to Nintendo DS game programs, Portable Playstation, Game Boy, Mobile Phone (Smartphone), iPad and several other types of 
tablets $^{14-15}$. Along with watching television and playing video games can cause a person to consume snacks in greater amounts and coupled with reduced physical activity, resulting in energy imbalances which are then associated with increased BMI or obesity ${ }^{16}$.

Research by Termini said that there are several gadget and media effects that contribute to obesity, but not directly to the obesity process yet to sedentary behaviors like: 1) Teaching diet and choosing unhealthy foods from TV shows and commercials, 2) Increasing snacking behavior when watching TV, 3) Reducing physical activity, 4) Interrupting normal sleep patterns ${ }^{17}$.

Screen time or excessive use of gadgets is associated with obesity in adolescents aged 11-16 years, and $68.9 \%$ of obese children have high screen time exceeding recommended times ${ }^{18-22}$. Another study conducted by Greca et al. in South Brazil proved that teens do more screen time than children $^{23}$. Obese teens often play smartphones while consume snacks, and snacks consumed are usually high in fat, sugar, and salt such as chocolate, cookies, and chips. Unwittingly they consume these snacks in large quantities and with high frequences. Excessive screen time is related to consumption of snacks and soft drinks for male and female adolesence. Kenny and Gortmaker found that the high use of smartphones, tablets, computers, and video games was related to the risk of obesity by $20 \%$ of participants using other display devices for $\geq 5$ hours of use every day. Students who do screen time of $\geq 5$ hours a day are almost 3 times more likely to consume sweet drinks every day, and almost twice as likely to be obese. Students who use other display devices $\geq 5$ hours a day are almost twice as likely to consume sweet drinks, lack of physical activity, and inadequate sleep duration ${ }^{24}$.

School children who do not have outdoor activities tend to spend time at home playing gadgets with a long duration. Angel explained that school children with low physical activity have a risk three times to become obese compared to school children who have varied physical activity every day $^{25,26}$. Research in other school children states that obese adolescents have a low level of activity, namely sitting while studying in school, little exercise during school, too long using electronic devices and lack of playing time outside ${ }^{27-28}$. Less physical activity in respondents was also supported by the results of a research by Greca et al, concluding that the prevalence of lack of physical activity in adolescents aged 13-17 years was $91.4 \%$, and they often carried out sedentary activities $>2$ hours a day at $71.8 \%^{23}$.

\section{Indirect Effect of Sleep Habit on Obesity}

Sleep habit have an indirect effect on obesity. The result showed that sleep habit affect obesity, through increased use of gadgets and physical activity. The relation of sleep habit to the gadget usage is quite strong and in the same direction, if sleep habit is bad then the gadget usage is high, and vice versa. This will affect activities and then affect BMI. In this research, it can be said that the sleep habit of adolescents who were respondents stated that their sleep hours were less with a percentage of $83.5 \%$ due to irregular sleep schedule and had to do schoolwork at night accompanied by playing games/gadget before going to bed so as to make teenagers are hard to start sleeping. The duration of night sleep in respondents who slept between 5-7 hours, or decreased sleep duration, the delay in sleep caused by the shift to the era of advanced technology, the information age, the internet, games in various countries ${ }^{25,29}$. Various supporting studies suggest that reduced sleep duration is associated with increased BMI and obesity prevalence, although it does not specify in detail whether it is a direct or indirect cause $\mathrm{s}^{30-33}$.

\section{Indirect Effects of Stress on Obesity}

Stress has an indirect effect on the occurrence of Obesity, namely through sleep habit and through gadgets usage. In this study the relationship between stress level variables on sleep habit with a strong and direct correlation, if stress is high, then sleep habit will also be bad, and vice versa. While the relation between stress variables and gadget usage is also quite strong and in the same direction, if the level of stress is high then gadget usage is also high, and vice versa. In this research, stress is the direct cause of gadget usage, in addition stress will affect sleep habit which can also affect the gadget usage. The gadget usage which then affects physical activity and so affects IMT.

When experiencing stress, the brain will stimulate adrenaline secretion. These chemical will get to the kidney and trigger the process of changing glycogen to glucose, so that it can accelerate blood circulation, blood pressure will increase, breathing faster, causing a person unable to sleep. In addition, the secretion of this hormone stimulates the activity of other organ systems including the digestive system. As stated in the results of the Lusia research, the main hormonal response to stress is activation of the corticotrophin releasing hormoneadrenocorticotropic hormone-cortisol system ${ }^{34}$. The process that occurs includes stimulation of the hypothalamus causing secretion of the hormone corticotrophin releasing hormone $(\mathrm{CRH})$, then stimulates the anterior pituitary to secrete $\mathrm{ACTH}$. Occurrence of increased secretion of $\mathrm{CRH}$ and $\mathrm{ACTH}$, causing the adrenal cortex to release cortisol excessively. The high levels of these hormones will stimulate the body to release the hormone insulin, leptin and the neuropeptide $Y$ (NPY) system which causes hunger so there is a desire to eat. This results in a build up of visceral fat and can increase BMI. The results of the research by Sanlier and Sominsky, found that stress levels associated with $\mathrm{BMI}^{35-36}$. Although 
different from the model produced in this study, where the increase in BMI through the poor sleep habit change first.

Stress can support the occurrence of obesity caused by behavior and metabolism ${ }^{37}$. A research in Canada, found a significant relation between obesity and jobs having high pressure or stress. This is the result of biological conditions and behavior of an individual who experiences stress $^{38}$. In this study, it can be said that stess can have an impact on behavior related to sleep habit of people who experience stress.

This study is inseparable from various limitations, such as methodology. This study used a crosssectional study design so that the possibility of recall bias was very high due to the limited memory of respondents. The results of the study are strongly influenced by the honesty of the respondents in answering the questions. To verify the research results, the researcher also asked the respondents directly to triangulate.

\section{CONCLUSION}

The results of this research found that the conclusions of the path diagram generated are as follow: 1) Gadget usage variable path coefficient value has a positive effect on physical activity. This means that if the gadget usage is good (the indicator is low / not addicted) it will make physical activity good. 2) Physical activity variable path coefficient value has a positive in effect on obesity. This means that if physical activity is good it will make teenagers not experience obesity. 3) Sleep habit and stress variable path coefficient value has a positive effect on gadget usage. This means that if sleep habit is good will make stress levels also good (low stress) and result in low or good gadget usage (making someone not addicted to gadget). It can be concluded that gadget addiction is directly related to sleep habits, stress, physical activity, and indirectly with obesity. The higher the intensity of using gadgets will have an effect on poor sleep habits, high levels of stress, and lower physical activity. This can put adolescents at risk of obesity.

\section{Conflict of interest}

The authors declare no potential conflict of interest.

\section{REFERENCES}

1. Gibney, M. J., Margetts, B., \& Kearney, J. Gizi Kesehatan Masyarakat. 2009.

2. WHO. Global Status Report on Noncommunicable Disease. 2011. Retrieved from

https://www.who.int/nmh/publications/ ncd_report_full_en.pdf
3. Suryaputra, K., \& Nadhiroh, S. R. Perbedaan Pola Makan dan Aktivitas Fisik Antara Remaja Obesitas dengan Non Obesitas. Makara Kesehatan 2012; 16(1), 45-50.

4. Departemen Kesehatan RI. Obesitas dan Kurang Aktivitas Fisik. 2009.

5. Kementerian Kesehatan RI. Riset Kesehatan Dasar (Riskesdas) 2013. 2013.

6. Febrino. Tindakan Preventif Pengaruh Negatif Gadget Terhadap Anak. Noura 2017; 1(1).

7. Tanjung S. Fajar. Intensitas penggunaan gadget dan obesitas anak prasekolah. BKM Journal of Community Medicine and Public Health 2017; 33(12), 603-608.

8. Adámková, V., Ek, J. A. H. Č., Lánská, V., Vrablík, M., Lesná, I. K., Suchánek, P., ... Veleminský, M. Association between Duration of the Sleep and Body Weight. Physiological Research 2009; 58.

9. Hamidin, A. S. Kebaikan Air Putih. 2011.

10. Park, S. Association Between Short Sleep Duration and Obesity Among South Korean Adolescents. Western Journal of Nursing Research 2011; 33(2). https://doi.org/https://doi.org/10.1177 \%2F0193945910371317

11. Riwidikdo, H. Statistik Terpan dengan Program R Versi 2.5.1. Yogyakarta. 2008.

12. Notoatmodjo, S. Metodologi Penelitian Kesehatan. 2012.

13. Arikunto, S. Prosedur Penelitian Suatu Pendekatan Praktek. 2010.

14. Lui, D. P. Y., Szeto, G. P. Y., \& Jones, A. Y. M. The Pattern of Electronic Game Use and Related Bodily Discomfort in Hong Kong Primary School Children. Computers \& Education 2011; 57(2), 1665-1674.

15. Cheung, L., \& Hu, F. The Obesity Prevention Source 2012.

16. Gregori, D., et al. 2013. How to Communicate Nutrition Information to People: The Attitudes of Chile Population toward Food. Open Obes J, 5: 36-42.

17. Termini, R. B., Roberto, T. A., \& Hostetter, S. G. Food Advertising and Childhood Obesity: A Call to Action for Proactive Solutions. Minnesota Journal of 
Law, Science \& Technology 2011, 12(2), 619-650.

18. Kehua, Y., Yan, L. C., Fang, Z. Y., Qian, L., Dong, W. X., Jian, C., ... Fen, J. H. Association between Screen Time and Obesity among Middle School Students in Shanghai. Journal of Environmental \& Occupational Medicine 2014. 31(6), 452455.

19. Shaheed dan Wijayanti. Bahaya gadget bagi anak. 2017.

20. Marttinen, R., Vernikoff, L., Phillips, S., \& Fletcher, N.. Physical Activity, Screen Time, and Obesity: A Statistical Inquiry into Latina/o Youth. Californian Journal of Health Promotion 2011; 15(1), 27-35.

21. Lucena, J. M. S. De, Cheng, L. A. Cavalcante, T. L. M., Da Silva, V. A., \& De Farias, J. C. Prevalence of excessive screen time and associated factors in adolescents. Revista Paulista de Pediatria 2015; 33(4), 407-414.

22. Oliver, C. S.. A Review of the Relationship between Screen Time and Low Levels of Physical Activity with Obesity and Sedentary Behaviors in Children and Adolescents. Georgia State University 2017; 5-12.

23. Greca, J. P. de A., Silva, D. A. S., \& Loch, M. R.. Physical activity and screen time in children and adolescents in a medium size town in the South of Brazil. Revista Paulista de Pediatria (English Edition) 2016; 34(3), 316-322. https://doi.org/10.1016/j.rppede.2016.0 1.001

24. Kenney, E. L., \& Gortmaker, S. L. United States Adolescents' Television, Computer, Videogame, Smartphone, and Tablet Use: Associations with Sugary Drinks, Sleep, Physical Activity, and Obesity. Journal of Pediatrics 2017; 182, 144-149.

https://doi.org/10.1016/j.jpeds.2016.11 .015

25. Angels, M. R., Marunduh, S. R., \& Rampengan, J. J. V. Gambaran Durasi Tidur pada Remaja dengan Kelebihan Berat Badan. Jurnal E-Biomedik (Ebm) 2013; 1(2), 849-853.

26. Handayani, O.W.K., Wiranti, I., Raharjo, B.B., Nugroho, E., The reproduction health behavior of high school teenagers in semarang, Indonesia. Open Public Health Journal 2019; 12(1): 309-314.
27. Rosen, L, Lim, A., Felt, J, Carrier, L, Cheever, N.., Lara-Ruiz, J, Rokkum, J. Media and technology use predicts illbeing among children, preteens and teenagers independent of the negative health impacts of exercise and eating habits L.D. Comput Human Behav 2014; 6, 247-253.

https://doi.org/10.1016/j.chb.2014.01.0 36

28. Kim, S.-E., Kim, J.-W., \& Jee, Y.-S. Relationship between smartphone addiction and physical activity in Chinese international students in Korea. Journal of Behavioral Addictions 2015; 4(3), 200205.

https: / /doi.org/10.1556/2006.4.2015.02 8

29. Istiqomah, S. N., Lisiswanti, R., Dokter, J. P., Kedokteran, F., Lampung, U., Kedokteran, B. P., Lampung, U. Dampak Eksposur Layar Monitor Terhadap Gangguan Tidur Dan Tingkat Obesitas Pada Anak Anak The Effect of Screen Time Exposure in Sleep Disorder and Obesity Level on Children. Majority 2017; 6(2), 72-77.

30. Garaulet, M., Ortega, F. B., Ruiz, J. R., Rey-López, J. P., Béghin, L., Manios, Y., ... Moreno, L. A. Short sleep duration is associated with increased obesity markers in European adolescents: Effect of physical activity and dietary habits. the HELENA study. International Journal of Obesity 2011; 35(10), 1308-1317. https://doi.org/10.1038/ijo.2011.149

31. Chaput, J. P., Leblanc, C., Pérusse, L., Després, J. P., Bouchard, C., \& Tremblay, A. Risk factors for adult overweight and obesity in the Quebec Family Study: have we been barking up the wrong tree? Obesity (Silver Spring, Md.) 2009; 17(10), 1964-1970.

https://doi.org/10.1038/oby.2009.116

32. Silva, M. L., Melo, R. J. P., Dabbicco, P., \& De Freita, C. M. S. M. Sleep during, overweight and obesity in adolescence: a systematic review. Manual Therapy, Posturology \& Rehabilitation Journal 2015; 12, 195. https://doi.org/10.17784/mtprehabjourn al.2014.12.195

33. Garmy, P., Clausson, E. K., Nyberg, P., \& Jakobsson, U. Insufficient Sleep Is Associated with Obesity and Excessive Screen Time Amongst Ten-Year-Old Children in Sweden. Journal of Pediatric Nursing 2018; 39, e1-e5. 
https://doi.org/10.1016/j.pedn.2017.11. 009

34. Nasrani, L., \& Purnawati, S. Perbedaan Tingkat Stres Antara Laki-Laki Dan Perempuan pada Peserta Yoga di Kota Denpasar. E-Jurnal Medika Udayana 2015; $4(12)$.

35. Sanlier, N., \& Unusan, N. The relationship between body weight and stres and nutritional status in Turkish women. Pakistan Journalof Nutrition 2007; 6(4), 339-344.

36. Sominsky, L., \& Spencer, S. J. (2014). Eating behavior and stress: a pathway to obesity. Frontiers in psychology 2014; 5 , 434. https: / / doi.org/10.3389/fpsyg.2014.0043 4

37. Handayani, O.W.K., Nugroho, E., Hermawati, B. Determinant of diabetes mellitus focusing on differences of Indonesian culture: Case studies in the Java and outer java region in Indonesia. Open Public Health Journal 2020; 13(1): 323-330

38. Sunhee Park. Association Between Short Sleep Duration and Obesity Among South Korean Adolescents: Western Journal of Nursing Research 2011; 33(2) 